\section{Repeatability and Minimum Selection Time for Fatty Acid Composition in Olive Progenies}

\section{León ${ }^{1}$}

Departamento de Agronomía, E.T.S.I.A.M., Universidad de Córdoba, Avda. Menéndez Pidal s/n, 14080 Córdoba, Spain

\section{L.M. Martín}

Departamento de Genética, E.T.S.I.A.M., Universidad de Córdoba, Avda. Menéndez Pidal s/n, 14080 Córdoba, Spain

\section{Rallo}

Departamento de Agronomía, E.T.S.I.A.M., Universidad de Córdoba, Avda. Menéndez Pidal s/n, 14080 Córdoba, Spain

Additional index words. Olea europaea L., oleic acid, olive breeding, variance components, year-to-year evaluation

Abstract. Fatty acid composition has been studied in seedlings from a diallel cross (nine families) among 'Arbequina', 'Frantoio', and 'Picual' olive (Olea europaea L.). Variance among samples within genotype, genetic and environmental (yearly) variances, and year-toyear consistency of data were estimated. A correlation analysis of the standardized data for fatty acid composition between first and second year data was also carried out to select the most interesting genotypes as early as possible. The results showed that fatty acid composition exhibit significant differences between genotypes and years. The variance component attributable to differences between genotypes represented $>60 \%$ of total variance for all the fatty acids evaluated. High correlation coefficients between the first and second year data were found for oleic and linoleic acid percentage; these correlations were slightly poorer for the other fatty acids analyzed. These results may be useful for improving the efficiency of olive breeding programs in first-stage selection on whole progeny populations.

Wide ranges of variability have been reported for the most important fatty acids in olive cultivar collections (Fontanazza and Patumi, 1994; Tous and Romero, 1993; Uceda et al., 1999) and samples of wild populations (Sedgley and Wirthensohn, 2000). However, many cultivars display a number of traits that are undesirable in a modern olive industry (Barranco and Rallo, 2000). This has encouraged olive breeding programs in some olive-producing countries. Currently, most breeding programs are based on cross-breeding, usually between cultivars of known merit, with the aim of combining the good qualities of both parents in some of the progeny. Fatty acid composition, in particular high oleic acid content, has been considered one of the most important breeding objectives (Fontanazza and Baldoni, 1990; Rallo, 1995).

In breeding programs, seedlings must be selected or discarded as soon as possible to decrease generation time and increase the success of breeding work (Allard, 1960), which is almost directly related to the space occupied by the progenies and the time used for their evaluation (Hansche, 1983). Therefore, it is

Received for publication 12 Dec. 2002. Accepted for publication 17 July 2003. This research was supported by grant INIA CAO99-008 of the Spanish Ministry of Agriculture, Food and Fisheries. Thanks are due to R. de la Rosa and A. Belaj for their critical review of the manuscript.

${ }^{1}$ Corresponding author; e-mail ag2lemol@uco.es.

HortScience Vol. 39(3) June 2004
Plant materials and evaluations. Seedlings from reciprocal crosses among 'Arbequina', 'Frantoio', and 'Picual' have been used in this study. Parents of the breeding program were chosen on the basis of known merit as oil-producing cultivars: high yield and oil content, and good oil quality (Rallo, 1995). Nevertheless, they come from different geographical areas ('Arbequina' from Catalonia, Spain; 'Frantoio' from Tuscany, Italy; and 'Picual' from Andalusia, Spain) and display a great variability in fatty acid composition. 'Arbequina' is characterized by its high palmitic and linoleic acids content, whereas 'Frantoio' and 'Picual' have smaller proportions of these fatty acids and higher proportion of oleic acid (Uceda et al., 1999).

Seedlings from crosses made in Spring 1992 were used in this study. Crosses were made by applying male pollen to female bagged branches and the problem of the long juvenile period was overcome by forced growth of seedlings in greenhouse (Santos-Antunes et al., 1999). The seedlings were transplanted into the field in 1994 at distances of $1.50 \mathrm{~m}$ in the row and $3.50 \mathrm{~m}$ between rows, and standard cultural practices were followed in the orchard to ensure tree growth. The experimental design was randomized blocks with nine crosses, four repetitions, and eight plants for elementary plot. Fatty acid composition was recorded in 1996 and 1997 once seedlings began to flower and bear. The number of seedlings per family evaluated each year for fatty acid composition is presented in Table 1. Fruit were collected at the same ripening index and kept frozen until analyzed by gas chromatography.

Fatty acid methyl esters (FAMEs) were determined according to the procedure of Garcés and Mancha (1993) to avoid the necessity of oil extraction before FAMEs preparation. A 50-mg sample of flesh tissue was boiled (80 ${ }^{\circ} \mathrm{C}$ for $2 \mathrm{~h}$ ) with a reagent mixture containing 39 methanol : 34 heptane : 20 toluene : 52 ,2dimethoxipropane: $2 \mathrm{H}_{2} \mathrm{SO}_{4}$ (by volume). After cooling at room temperature, two phases were formed with the upper containing FAMEs ready for gas chromatography analysis. Ten random samples per genotype (each for a single fruit) were prepared. Separation of FAMEs was carried out using a flame ionization detector gas chromatograph equipped with a BPX-70 column (50 m, 0.25 mm I.D., $0.22 \mu \mathrm{m}$ film thickness). This method allowed quick processing of a high number of samples for fatty acid composition of olive oil. In this work, only the main fatty acids were considered: palmitic (C16:0), palmitoleic (C16:1), stearic (C18:0), oleic (C18:1), and linoleic (C18:2).

Data analysis. The measurements from 2, 4,6 , or 8 samples taken randomly from the 10 samples evaluated in 1996 were subjected to analysis of variance to obtain estimates of error variance (variance associated with samples within genotype). Least significant differences at rejection level 0.05 and ranking of genotypes according to the number of samples were also compared.

ANOVA was also performed with genotype and year to calculate variance components and 
Breeding, Cultivars, Rootstocks, and Germplasm Resources

Table 1. Number of seedlings evaluated and mean values obtained for the different fatty acids in each family. Palmitic (C16:0), palmitoleic (C16:1), stearic (C18:0), oleic (C18:1), and linoleic (C18:2) acids.

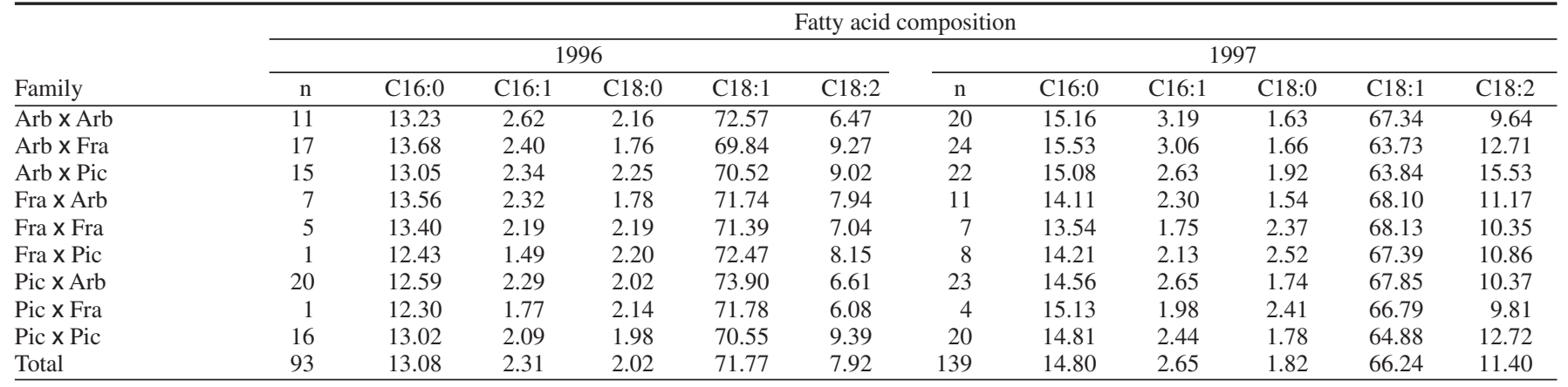

repeatability. To avoid unbalanced design, only those genotypes that were evaluated in both years have been included in the model. The additive linear model for the statistical analysis was $P_{i j}$ $=\mu+g_{i}+y_{j}+e_{i j}$, where $P_{i j}$ is the phenotypic value of the ith genotype in the jth year, $\mu$ is overall mean, $\mathrm{g}_{\mathrm{i}}$ is the genotype effect, $\mathrm{y}_{\mathrm{i}}$ is the year effect, and $e_{\text {i. }}$ is the residual effect. From this model, repeatability (r) was estimated as $r$ $=\sigma_{G}^{2} /\left(\sigma_{G}^{2}+\sigma^{2} / l_{y}\right)$, where $\sigma_{G}^{2}$ is the variance between genotypes, $\sigma^{2}$ is the residual variance, and $n_{y}$ the number of years evaluated. Analysis were performed using ANOVA procedure of SAS software (SAS, Cary, N.C.).

Correlation coefficients among the data obtained in the first and second year were calculated to determine the consistency of year-to-year data. Data were previously normalised using the mean and SD for each year and Pearson's correlation coefficient was calculated using the statistical package Statistix (Analytical Software).

\section{Results and Discussion}

Optimal number of samples and repeatability over years. Variance of samples within

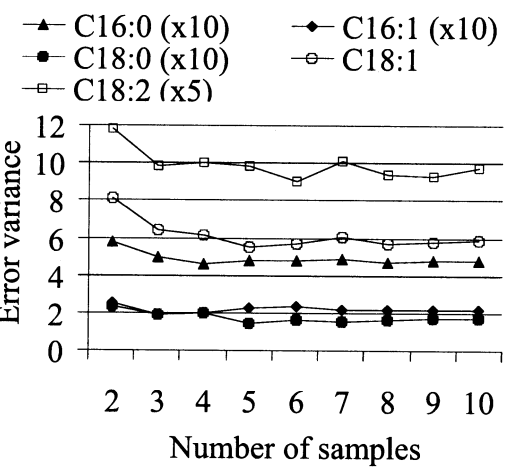

genotype was negligibly small compared to variance between genotype for all the fatty acids evaluated. In all cases, error variances and least significant differences at a rejection level of 0.05 decreased when increasing the number of samples used for their determination, although they seem to level off at five to six samples (Fig. 1).

The ranking of genotypes obtained for the different fatty acids evaluated varies according to the number of samples used. Great differences in the order of genotypes were observed for oleic acid percentage comparing the ranking obtained from two or ten samples, but these differences were hardly important when comparing the ranking obtained from six or ten samples (Fig. 2). In all cases, ranking differences were highest in the middle of the range of variation. It seems, therefore, that the risk of incorrect selection is not very important from five to six samples.

Significant differences between genotypes and years were found for all the fatty acids analyzed (Table 2). However, variance due to yearly differences was negligible for all the fatty acids, residual variance was only important for palmitoleic and stearic acids, and

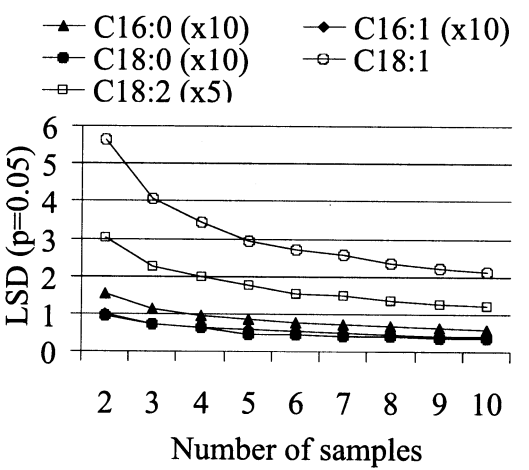

Fig. 1. Error variance (variance associated with samples within genotype) and least significant differences at rejection level 0.05 for the different fatty acids analyzed according to the number of samples ( 2 to 10) used for their determination. Palmitic (C16:0), palmitoleic (C16:1), stearic (C18:0), oleic (C18:1), and linoleic (C18:2) acids. genotype variance was the main contributor to total variance for all the fatty acids (Fig. 3). As a consequence, the repeatability estimated from the two year data generally showed high values for all the fatty acids analyzed (Table 2 ). These values ranged from 0.75 for stearic acid to 0.90 for linoleic acid.

According to Hansche (1983), there are four distinct ways for reducing the effects of environmental variation on measurements of important traits: by reducing variation in the environment in which the breeding stock is reared, by improving measurement techniques, by estimating the effects of environment and adjusting measurements accordingly, or by replicating measurements. Repeated measurements on each genotype can be done by measuring several samples from the same plant, different plants of the same genotype, or different years on the same plant. In other fruit breeding programs, an increase in the number of years instead of the number of tree replications has been reported to be more effective and the variance among samples was higher than the variance among trees of the same genotype for characters such as the soluble solids concentration in persimmon or cherry (Hansche and Beres, 1966; Iezzoni, 1986; Yamada et al., 1993). The results obtained in this work indicate that the fatty acid evaluation of five to six samples could provide enough accuracy to select the most interesting genotypes. On the other hand, analysis of variance performed with genotypes and years showed a large genotype variance for all the fatty acids evaluated. The high repeatability obtained for fatty acid composition suggests that the values obtained for these characters in the first year could be reliable indicators of the values obtained next year. Similar results have been reported in studies on the influence of cultivar and environment on the fatty acid composition of olive oil (Tous and Romero, 1994; Uceda et al., 1999), in which a strong genetic component was observed. Fatty acid

Table 2. Mean square and repeatability for fatty acid composition. Palmitic (C16:0), palmitoleic (C16:1), stearic (C18:0), oleic (C18:1), and linoleic (C18:2) acids.

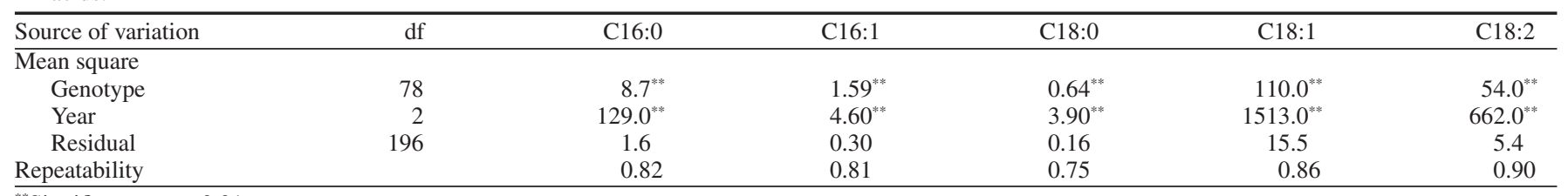

Repeatability

0.82

0.81

0.75

HortScience Vol. 39(3) June 2004 


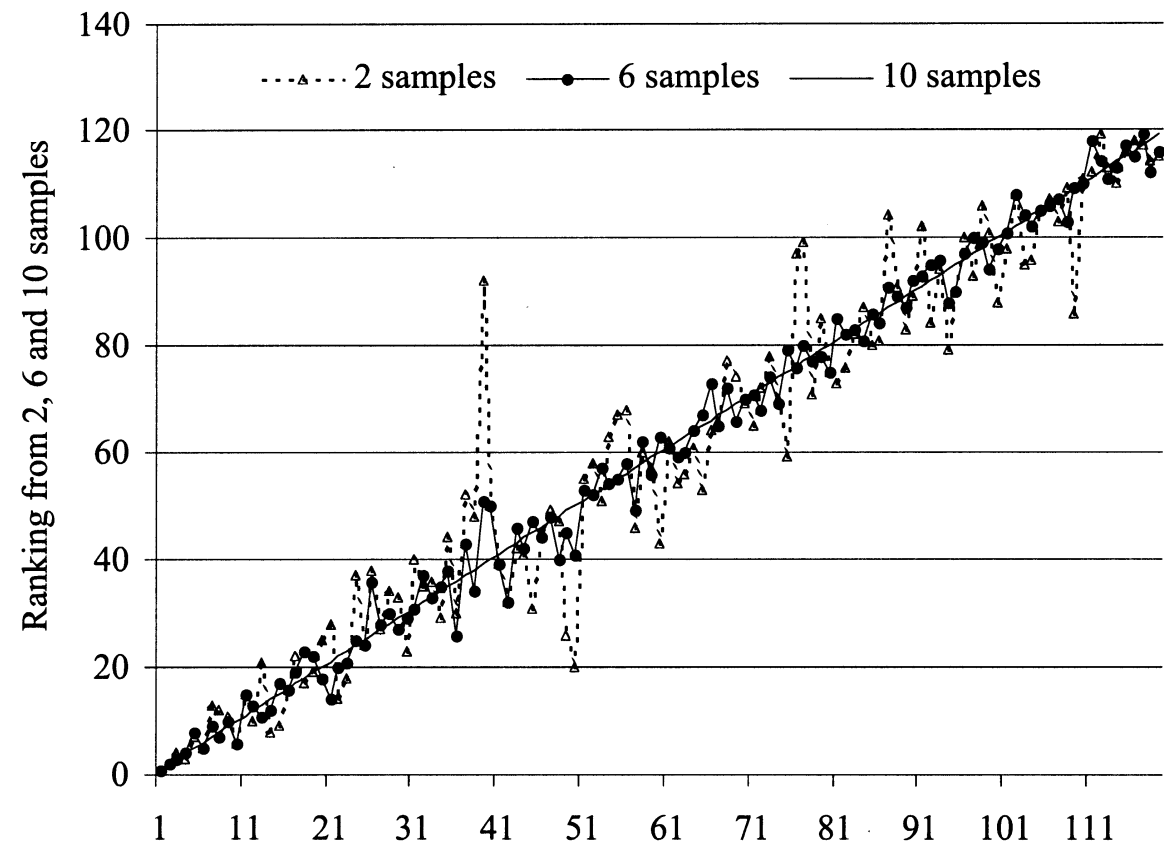

Fig. 2. Ranking of genotypes for oleic acid content according to the number of samples $(2,6$, or 10) used for its determination.

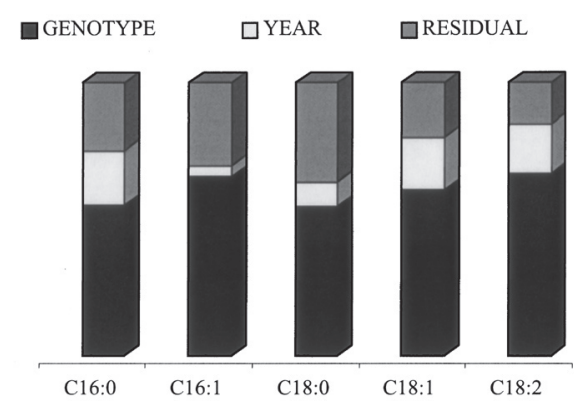

Fig. 3. Variance between genotypes, years and residual (expressed as percentage of total variance) for the different fatty acids evaluated. Palmitic (C16:0), palmitoleic (C16:1), stearic (C18:0), oleic (C18:1), and linoleic (C18:2) acids

composition was more influenced by cultivar ( $>60 \%$ of total variance) than by different environmental factors such as year, season, or location. Similar results were also found for the fatty acid composition of almond kernels from

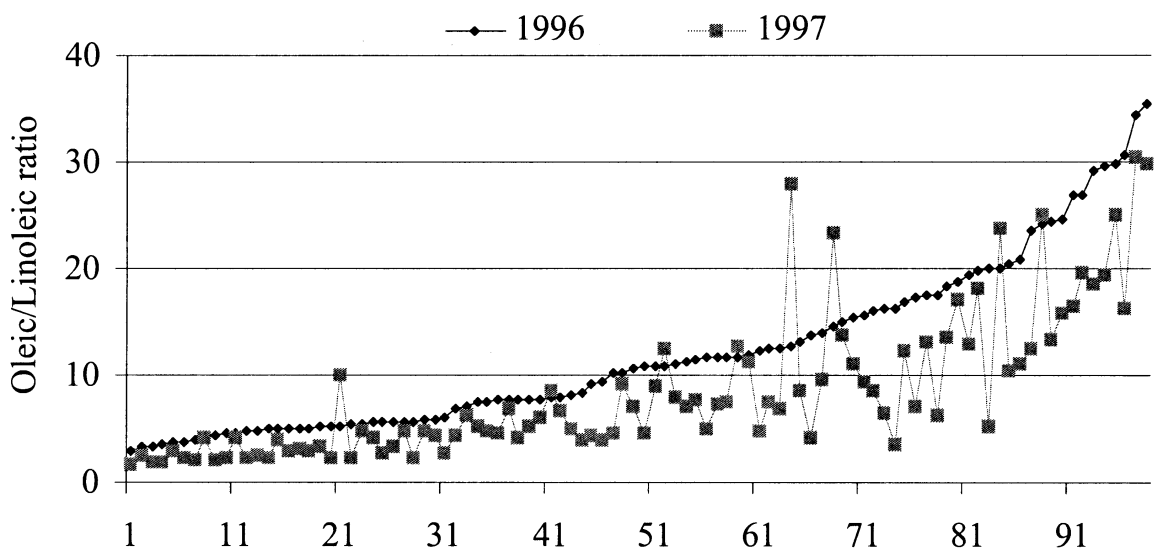

Fig. 4. Ranking of genotypes for ratio of oleic to linoleic acids in 1996 and 1997.
Nevertheless, high correlation coefficients were obtained between the first and second year data for all the fatty acids analyzed, ranging from 0.75 for stearic acid to 0.90 for linoleic acid (Fig. 5). Moreover, most genotypes with fatty acid content higher or lower than the mean of the first year (i.e., positive or negative normalized values respectively) showed the same trend in the following year. We aim to obtain new cultivars with a high percentage of oleic acid and low percentage of linoleic acid. Therefore, for the oleic acid percentage, the most interesting genotypes are located in the first quadrant of the scatter plot, i.e., those for which positive normalized values were obtained in both years. On the contrary, those genotypes with negative values in both years could be discarded. The genotypes located in the other quadrants are more complicated, particularly those with negative values the first year and positive the next, which would be eliminated based on the first year data only, resulting in the possibility of potentially interesting genotypes being discarded.

The opposite situation applies to linoleic acid. In this case, the most interesting genotypes are located in the third quadrant, i.e. those for which negative normalized values were obtained in both years. Those genotypes with positive values in both years could be discarded. In this case, the most complicated genotypes to select would be those with negative values the first year and positive the next because such a selection result in potentially poor genotypes being selected. Similar results were obtained for the other fatty acids evaluated, although correlation coefficients were slightly lower than was the case for the oleic or linoleic acids.

In summary, the results obtained in this work indicate that the fatty acid evaluation of five to six samples per genotype in the first year of bearing could be used to select the most interesting genotypes, mainly in firststage selection on the whole progeny populations. Based on these results, some interesting genotypes have been selected and propagated for evaluating their agronomic behavior in comparative field trials. Searches for characters in the juvenile stage that are highly correlated with fruit characteristics in the mature tree, particularly fatty acid composition of oil, would be also of considerable value for early selection in progenies.

\section{Literature Cited}

Abdallah, A., M.H. Ahumada, and T.M. Gradziel. 1998. Oil content and fatty acid composition of almond kernels from different genotypes and California production regions. J. Amer. Soc. Hort. Sci. 123:1029-1033.

Allard, R.W. 1960. Principles of plant breeding. John Wiley and Sons, New York.

Ayton, J., R.J. Mailer, K. Robards, B. Orchard, and M. Vonarx. 2001. Oil concentration and composition of olives during maturation in south-western New South Wales. Austral. J. Expt. Agr. 41:815-821.

Barranco, D. and L. Rallo. 2000. Olive cultivars in Spain. Hortechnology 10:107-110.

Bellini, E. 1992. Behaviour of some genetic characters in olive seedlings obtained by cross-breeding. 
Palmitic acid

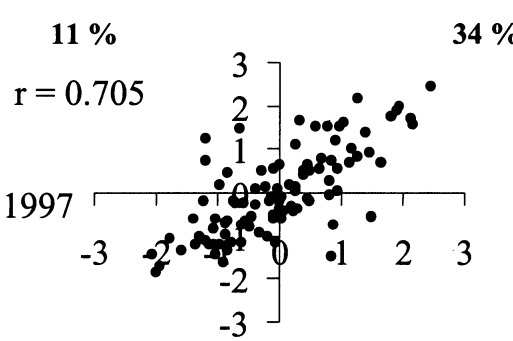

$41 \%$

1996

$14 \%$

Stearic acid

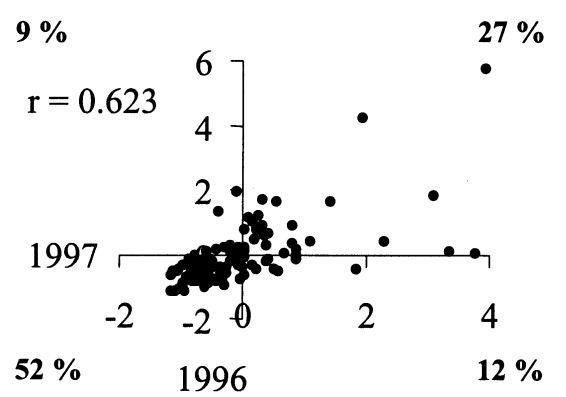

Linoleic acid

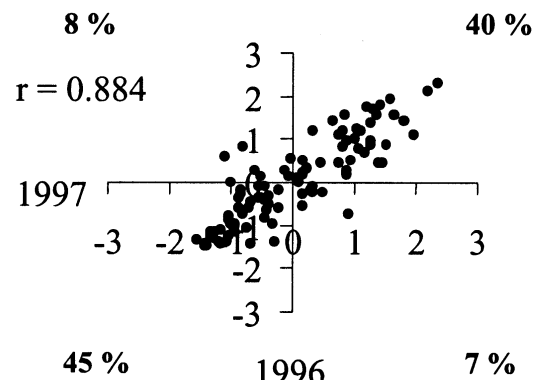

Acta Hort. 317:197-208.

Fontanazza, G. and L. Baldoni. 1990. Proposed programme for the genetic improvement of the olive. Olivae 34:32-40.
Palmitoleic acid

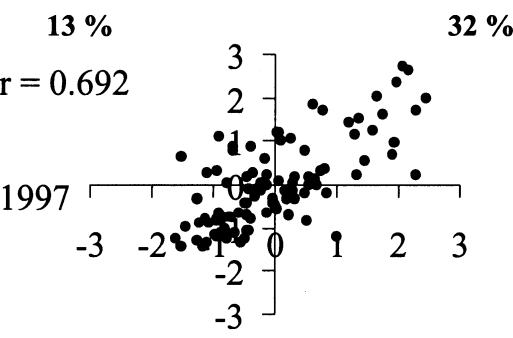

$43 \%$

1996

$12 \%$

Oleic acid

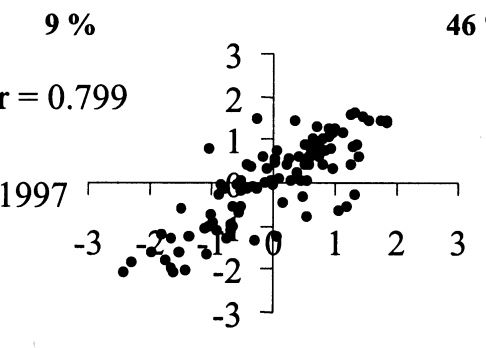

$37 \% \quad 1996$

$8 \%$

Fig. 5. Scatter plots and correlation coefficients between normalized data obtained the first and second years for the different fatty acids. Percentages of genotypes in each quadrant are indicated.

Fontanazza, G. and M. Patumi. 1994. Influence of cultivars on the composition and quality of olive oil. Acta Hort. 356:358-361.

Fontanazza, G., G. Vergari, M.Patumi, and G. Giorio.
1999. Preliminary results of the evaluation of yield components in an $\mathrm{F}_{1}$ segregant population of olive seedlings from the cross Leccino x Kalamata. Acta Hort. 474:97-101.

Garcés, R. and M. Mancha. 1993. One-step lipid extraction and fatty acid methyl esters preparation from Fresh plant tissues. Anal. Biochem. 211:139-143.

Hansche, P.E. 1983. Response to selection, p. 154-171. In: J.N. Moore and J. Janick (eds.). Methods in fruit breeding. Purdue Univ. Press, West Lafayette, Ind.

Hansche, P.E. and V. Beres. 1966. An analysis of environmental variability in sweet cherry (Prunus avium L.). Proc. Amer. Soc. Hort. Sci. 88:167-172.

Iezzoni, A.F. 1986. Variance components and sampling procedures for fruit size and quality in sour cherry. HortScience 21:1040-1042.

Lavee, S. 1990. Aims, methods and advances in breeding of new olive (Olea europaea, L.) cultivars. Acta Hort. 286:23-36.

Lavee, S. and M. Wodner. 1995. The effect of growing region, maturation and fruit handling on oil quality of cv. 'Nabali' olives in the West bank mountains. Agr. Med. 125:395-403.

Pannelli, G., M. Servili, R. Selvaggini, M. Baldioli, and G.F. Montedoro. 1994. Effect of agronomic and seasonal factors on olive (Olea europaea $\mathrm{L}$.) production and on the qualitative characteristics of the oil. Acta Hort. 356:239-243.

Perri, E., M.V. Parlati, A. Palopoli, M. Pellegrino, and B. Rizzuti. 1999. Characterization of Italian virgin olive oils using fatty acids. Acta Hort. 474:627-630.

Rallo, L. 1995. Selection and breeding of olive in Spain. Olivae 59:46-53.

Santos-Antunes, A.F., A. Mohedo, I. Trujillo, and L. Rallo. 1999. Influence of the genitors on the flowering of olive seedlings under forced growth. Acta Hort. 474:103-105.

Sedgley, M. and M. Wirthensohn. 2000. The Australian olive improvement programme. Olivae 83:27-30.

Tous, J. and A. Romero. 1993. Variedades de olivo. Fundación "La Caixa", Barcelona, Spain.

Tous, J. and A. Romero. 1994. Cultivar and location effects on olive oil quality in Catalonia, Spain. Acta Hort. 356:323-326.

Uceda, M., M.Hermoso,A. García-Ortiz,A. Jiménez, and G. Beltrán. 1999. Intraspecific variation of oil contents and the characteristics of oils in olive cultivars. Acta Hort. 474:659-662.

Yamada, M., H. Yamane, K. Yoshinaga, and Y. Ukai. 1993. Optimal spatial and temporal measurement repetition for selection in japanese persimmon breeding. HortScience 28:838-841. 